\title{
Atmospheric contribution to eutrophication of the Adriatic Sea
}

\author{
V. Djuricic, C. Kosanovic \& J. Skevin-Sovic \\ Air Quality Department, \\ Meteorological and Hydrological Service of Croatia, Croatia
}

\begin{abstract}
Eutrophication is an important problem, especially in semi-enclosed sea like the Adriatic Sea, a part of the Mediterranean Sea. A series of undesirable events occured in the Adriatic Sea in the past decades: invasions of jellyfish and other species, hypertrophic formations of mucilagenous aggregates, an increased frequency of toxic dynoflagellate appearance. It has been discussed that the atmospheric input of pollutants to the Mediterranean Sea is of the same order of magnitude as the riverine input for many species. It is also well known that precipitation is a very efficient scavenger of pollutants. The purpose of this paper is to evaluate the contribution of atmospheric pollution to the eutrophication of the Adriatic. For that purpose, inorganic nitrogen atmospheric input considered as wet deposition of $\mathrm{NO}_{3}{ }^{-}-\mathrm{N}$ and $\mathrm{NH}_{4}{ }^{+}-\mathrm{N}$ ions was investigated. Nitrate and ammonium concentrations in daily precipitation samples at three stations (two coastal and one on the island), for the 2001-2010 period were analysed. The Adriatic coast is under the combined influence of local, regional and longdistance pollution sources. Yearly wet deposition of $1-2 \mathrm{~g} \mathrm{~N} / \mathrm{m}^{2}$ significantly contribute to ecological imbalance and eutrophication. The Adriatic is ecologically very sensitive, because of its geographic position, complex orography, specific meteorological conditions and number of pollution sources. Predominant airflow is from the land to the sea. The precipitation amount is high in the area of the highest air pollution, which results in high wet deposition.

Keywords: eutrophication, Croatian Adriatic coast, inorganic nitrogen wet deposition.
\end{abstract}




\section{Introduction}

Man can disturb the natural environment in many ways, particularly when disposing of the waste resulting from his activities. A prime example of this is the influx of man-made nutrients, mainly in the form of nitrogen and phosphorus compounds, to estuary and coastal areas, which may result in the long-term decline of marine life. Though we often think of nutrients as being beneficial to life, an overabundance may cause perceptible water quality deterioration as well as chronic or intermittent health hazards, including toxicity and the loss of aesthetic and hence recreational values of affected waters (Pearl [1]). Investigations of the biogeochemical cycles of trace elements in marine systems in Croatia have placed increased significance on atmospheric input (Eskinja et al. [2]). It has been suggested that in open ocean waters, the flux of growthlimiting macronutrients, such as nitrogen, and micronutrients, such as iron, may constrain marine productivity, a major skin for atmospheric $\mathrm{CO}_{2}$ (Pearl [3], Knap et al. [4], Fanning [5], Pearl et al. [6], Willey and Cahoon [7], Owens et al. [8], Michaels et al. [9]). Studies of coastal estuaries, such as Chesapeake Bay (US), have shown that atmospherically derived dissolved inorganic nitrogen $\left(\mathrm{NO}_{3}{ }^{-}+\right.$ $\mathrm{NH}_{4}{ }^{+}$, components of acid rain) contributes $25-35 \%$ of the total loading of this primary nutrient (Fisher and Oppenheimer [10], Hinga et al. [11]).

In the northern Adriatic, the predominant sources of anthropogenic atmospheric nitrogen emission are attributed to fossil fuel combustion, the oil and petroleum industry and transportation, while in the mid and south Adriatic mainly to agricultural production. The effects are extensive algal blooms and oxygen depletion. It has been discussed that eutrophication on a regional level occurs in the northern Adriatic, and also, at a local level, in several coastal areas with periodic extremely negative consequences for the ecosystem and various human activities. Furthermore, a series of undesirable events occurred in the past decades: invasions of jellyfish and other species, hypertrophic formations of mucilaginous aggregates and an increased frequency of toxic dynoflagellate appearance (Smodlaka [12]).

It is well known that precipitation is a very efficient scavenger of pollutants. Changes in the chemical composition of precipitation reflect changes in the chemical composition of the atmosphere, resulting in deposition. It has been discussed that the atmospheric input of pollutants to the Mediterranean Sea is of the same order of magnitude as the riverine input for many species (Erdman et al. [13]). Since the Mediterranean Sea is a semi-enclosed sea, the effects of atmospheric transport and deposition are expected to be higher than in regions like open oceans. The same implies to the Adriatic Sea, which is also semienclosed and ecologically very sensitive because of its geographic position, complex orography, specific meteorological conditions and number of pollution sources. Predominant airflow is from the land to the sea. The precipitation amount is high in the area of the highest air pollution, which results in high wet deposition.

In Croatia, the Meteorological and Hydrological Service (DHMZ) have been monitoring and researching atmospheric precipitation quality and air pollution 
since the early eighties, last century. Over the last few decades, the DHMZ has taken an active part in the investigation of pollutant deposition. Research has been focused on the effects of acid rain, particularly those of sulphuric and nitric acids on forests (Bajic and Djuricic [14], Vidic [15], Alebic-Juretic and Sojat [16], Sojat et al. [17], Pozar-Domac et al. [18], Sojat and Borovecki [19]).

The aim of this paper is to address the problem by focusing on nitrogen wet deposition. For that purpose, nitrogen compounds and the $\mathrm{pH}$ value of daily, bulk precipitation samples for the period 2001-2010 have been analysed for three stations (two coastal and one on the island). The results are shown as basic statistic parameters of concentration and wet deposition.

\section{Material and methods}

\subsection{Study area}

Three stations on the Adriatic coast considered in this paper (Figure 1) belong to the monitoring network of precipitation chemistry, established and maintained by the Meteorological and Hydrological Service of Croatia (DHMZ). All of them are located at meteorological stations.

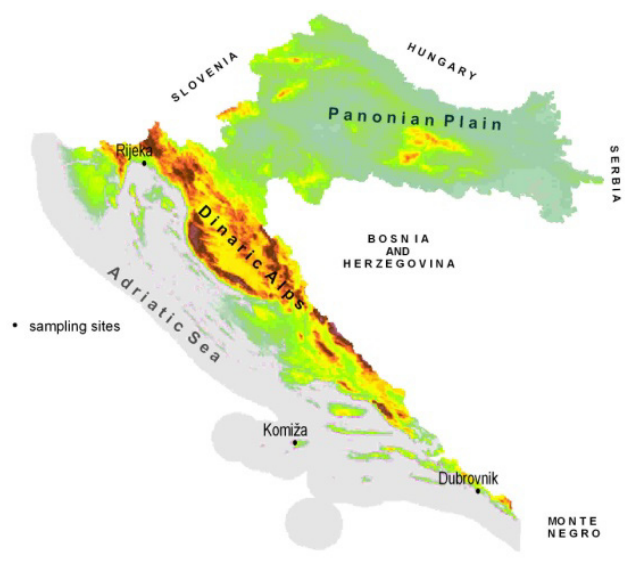

Figure 1: $\quad$ Sampling sites for precipitation quality on the Croatian Adriatic coast which are considered in this paper.

Rijeka $\left(\varphi=45^{\circ} 20^{\prime} \mathrm{N}, \lambda=14^{\circ} 27^{\prime} \mathrm{E}, \mathrm{h}=120 \mathrm{~m}\right.$ asl $)$ is the largest Croatian shipyard and harbour on the Adriatic coast, situated in the Kvarner Bay in the northern Adriatic. In addition, a great number of pollution sources are assembled here: an oil refinery and petroleum industry, a cokery, a thermal power plant, local industries, heavy traffic, domestic heating. The meteorological station is situated on a hill slope in the northern part of the city, about $2 \mathrm{~km}$ from the city centre. The station is under the influence of local and regional pollution sources, 
but emission of pollution from the above mentioned local sources was decreased in the considered period, compared to the period before 1991.

Dubrovnik $\left(\varphi=42^{\circ} 39^{\prime} \mathrm{N}, \lambda=18^{\circ} 5^{\prime} \mathrm{E}, \mathrm{h}=52 \mathrm{~m}\right.$ asl $)$ is a southern Adriatic station. It is open to the sea in all directions except to the west, and under the strong sea influence, especially in cases with jugo, a strong southern wind. There are no significant anthropogenic pollution sources in the region.

Komiza $\left(\varphi=43^{\circ} 3^{\prime} \mathrm{N}, \lambda=16^{\circ} 6^{\prime} \mathrm{E}, \mathrm{h}=20 \mathrm{~m}\right.$ asl $)$ is the station in a small fishing village, on the island of Vis in the southern Adriatic. This offshore monitoring site is open to the sea from all three directions and under the strong sea influence, especially in cases with jugo, a strong southern wind. There are no significant anthropogenic pollution sources in the region. Residents occasionally dispose of building materials close to the station.

\subsection{Sampling and analysis}

The daily bulk precipitation samples are collected in open polyethylene buckets in accordance with the precipitation measurement protocol; from 07 to 07 CET. Samples are transported to the laboratory twice a month. All samples are analysed in the chemical laboratory of the DHMZ, according to EMEP manual (EMEP-CCC Report [20]).

Radiometer PHM93 pH-meter with glass electrodes is used for $\mathrm{pH}$ measurements. Major ions are determined by ion chromatography: nitrates on Dionex 500 while ammonium on Dionex 1000.

The accuracy of analytical results is ensured by participation in interlaboratory intercomparisons organized by EMEP, GAW, the International School of Ion Chromatography and the NEU project. The data set was revised only by visual inspection.

\subsection{Statistical methods}

The annual volume-weighted concentration of specific ion (C) was calculated using the following relationship:

$$
C=\frac{\sum_{i=1}^{n} C_{i} P_{i}}{\sum_{i=1}^{n} P_{i}}
$$

where $n$ is the number of non-missing daily values in one year interval, $C_{i}$ is the daily concentration of a given ion, and $P_{i}$ is the daily precipitation measured by the standard rain gauge.

Annual wet deposition of a specific ion is the product of the annual volumeweighted concentration calculated by eqn. (1) and total annual precipitation amount. 


\section{Results and discussion}

\subsection{Precipitation quality}

The major statistic parameters of the analysed precipitation samples are given in Table 1. The largest precipitation amount fell in Rijeka, while the average annual precipitation amount at the offshore station Komiza was almost only half of the amount in Rijeka. Dubrovnik was between these two. The number of samples was consequently the largest in Rijeka, less in Dubrovnik and the smallest in Komiza. The mean annual precipitation amount in the period 2001-2010 compared with the climate period 1971-2000 (Zaninovic et al. [21]) was smaller in the northern Adriatic (Rijeka, 98\%) and bigger in the southern Adriatic (Dubrovnik, 113\%).

The precipitation regime in Croatia is the consequence of passing cyclones and related atmospheric fronts, within the general circulation of the atmosphere. Moisture maritime air masses from the Mediterranean Sea or the Adriatic Sea face the developed orography of Dinarides which force them to lift, resulting in condensation, convective cloudiness and precipitation. The mean annual precipitation amount is the smallest on the outer islands of the southern Adriatic and increases towards the coast.

Table 1: $\quad$ Statistic parameters of analyzed precipitation in Rijeka, Dubrovnik and Komiza in the period 2001-2010.

\begin{tabular}{|c|c|c|c|}
\hline Parameter & Rijeka & Dubrovnik & Komiza \\
\hline $\mathrm{N}$ & 1107 & 904 & 775 \\
\hline $\mathrm{RR}_{\text {tot }}\left(\mathrm{L} / \mathrm{m}^{2}\right)$ & 1525.8 & 1216.4 & 832.7 \\
\hline Efficiency (\%) & 99.1 & 98.7 & 98.7 \\
\hline $\mathrm{pH}$ avg & 5.09 & 5.63 & 5.48 \\
\hline $\mathrm{pH}$ min & 3.28 & 4.27 & 3.94 \\
\hline $\mathrm{pH}$ & 8.74 & 8.06 & 8.06 \\
\hline$\left(\mathrm{NO}_{3}{ }^{-}-\mathrm{N}\right)_{\text {avg }}(\mathrm{mg} / \mathrm{L})$ & 0.52 & 0.44 & 0.42 \\
\hline$\left(\mathrm{NH}_{4}{ }^{+}-\mathrm{N}\right)_{\text {avg }}(\mathrm{mg} / \mathrm{L})$ & 0.41 & 0.42 & 0.26 \\
\hline
\end{tabular}

$\mathrm{N}=$ number of samples; $\mathrm{RR}_{\mathrm{tot}}=$ mean annual precipitation amount in the period 20012010; Efficiency = chemically analyzed precipitation amount in mm divided by total precipitation amount in $\mathrm{mm}$ (expressed in \%); $\mathrm{pH}_{\mathrm{avg}}=$ precipitation volume weighted average $\mathrm{pH}$ value of all samples; $\mathrm{pH}_{\min }=$ minimum $\mathrm{pH}$ value of daily sample; $\mathrm{pH}_{\max }=$ maximum $\mathrm{pH}$ value of daily sample; $\left(\mathrm{NO}_{3}{ }^{-} \mathrm{N}\right)_{\text {avg }}=$ precipitation volume weighted nitrate average concentration of all samples; $\left(\mathrm{NH}_{4}{ }^{+}-\mathrm{N}\right)_{\text {avg }}=$ precipitation volume weighted ammonium average concentration of all samples.

Efficiency of the analyses was around $99 \%$, mainly due to samples with small amount of precipitation which was not enough for the analysis.

On average, precipitation in the northern Adriatic is still acid $\left(\mathrm{pH}_{\mathrm{avg}}\right.$ in Rijeka, Table 1, Figure 2), although not so as it was before. Mean annual $\mathrm{pH}$ value in Rijeka in the period 1981-1995 was 4.75 (Djuricic et al. [22]), while in the long period 1981-2006 it was 4.83 with the increasing trend (Spoler Canic et al. 
[23]). Percentage of acid rain varied between $20 \%$ and $50 \%$ in the period $2001-$ 2010 , but $\mathrm{pH}$ of individual samples varied between 3.28 and 8.74 . On the island in the south Adriatic precipitation was slightly acid and even more acid than before (pH of 5.48 in Komiza compared to 5.63 for the period 1981-2006 (Spoler Canic et al. [23])). On the other hand, on the southern Adriatic coast precipitation was not acid on average, although minimum $\mathrm{pH}$ value of individual sample was 4.27 (Dubrovnik, Table 1). Compared to some previous reports, precipitation acidity in the south also decreased ( $\mathrm{pH}$ of 5.63 compared to 5.53 for the period 1981-2006 in Spoler Canic et al. [23] and to 5.12 for the period 19811995 in Djuricic et al. [22]).

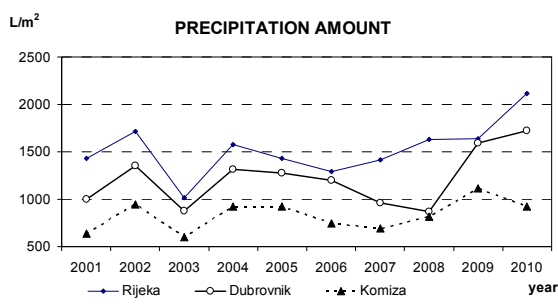

pH

pH

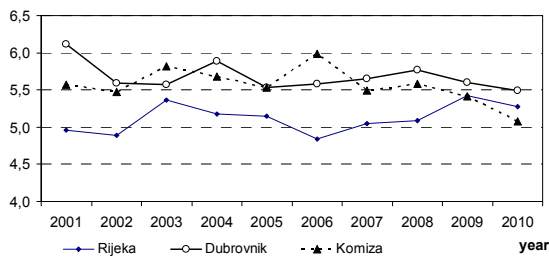

$\mathrm{mg} / \mathrm{L} \quad$ NITRATE
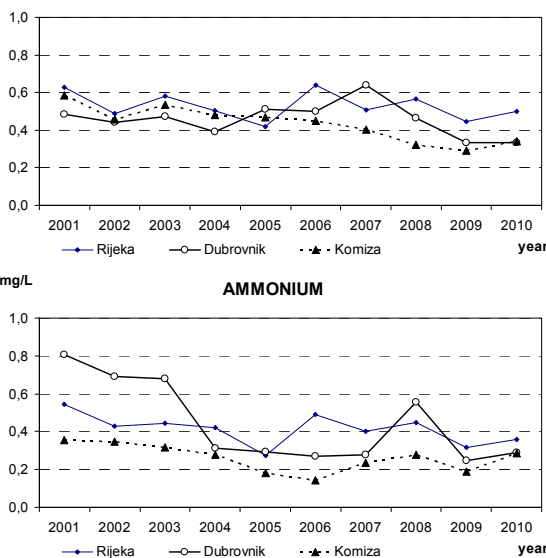

Figure 2: Annual precipitation amount and precipitation volume-weighted annual means of $\mathrm{pH}$ value, nitrate and ammonium concentrations in Rijeka, Dubrovnik and Komiza in the period 2001-2010. 
Concentration of nitrates in precipitation was on average the highest in the Northern Adriatic and the lowest on the island. However, differences are not big; annual means varies between $0.29 \mathrm{mg} / \mathrm{L}$ in Komiza in 2009 and $0.64 \mathrm{mg} / \mathrm{L}$ in Dubrovnik in 2007 and Rijeka in 2006 (Figure 2). Compared to the long-term period 1981-2006, and especially to the period 1981-1995, nitrate concentration was significantly lower in the last decade. This is in agreement with the decreasing trend showed in Spoler Canic et al. [23] and the fact that $\mathrm{NO}_{\mathrm{x}}$ emission in Europe and Croatia has decreased since 1990. The downward trend has been smaller or even disappeared after 2000 (Sutton et al. [24]) which was reflected in annual nitrate concentrations at Croatian sites at the coast, but not on the island.

The average concentration of ammonium in precipitation for the whole decade was almost the same at both coastal sites and smaller on the island (Table 1). However, ammonium concentrations were much higher in Dubrovnik from 2001 to 2004 and again in 2008. Ammonium concentrations in the last decade were approximately $40-46 \%$ lower on the southern and northern Adriatic coast respectively, and $10 \%$ lower on the island, compared to the long-term period 1981-2006 and 1981-1995.

\subsection{Nitrogen wet deposition}

Annual wet deposition of nitrogen from nitrates and ammonia, as well as total nitrogen are given in Figure 3. The northern Adriatic coast, represented by Rijeka, received the greatest amount of nitrogen wet deposition, between 0.99 and $1.82 \mathrm{~g} / \mathrm{m}^{2}$ per year. Most of that was from nitrates (53-60\% per year). It was mentioned before that the Rijeka area is one of the most polluted areas on the eastern Adriatic coast. Local industry and heavy traffic contribute to that. Despite the decrease in emission of pollution from industrial sources, the Rijeka area is still the most polluted area, mainly due to heavy traffic. However, nitrate deposition in the last decade decreased by $50 \%$ while ammonium deposition by 56\% compared to the period 1981-1995 (Djuricic et al. [22]).

Model calculations at the end of the last century, when pollution in the whole of Europe was higher, showed that $88-97 \%$ of oxidised and $58-78 \%$ of reduced nitrogen came to Croatia from neighbouring countries (EMEP [25]). On the other hand, $81-95 \%$ of oxidised and $56-67 \%$ of reduced nitrogen from Croatian sources was deposited in Croatia.

The southern Adriatic coast, represented by Dubrovnik, received a little bit less total nitrogen wet deposition than Rijeka, between 0.87 and $1.53 \mathrm{~g} / \mathrm{m}^{2}$. In four out of ten years, ammonium deposition was higher than nitrate, otherwise nitrate deposition prevail with $53 \%$ to $70 \%$. Higher ammonium deposition probably belongs to developed agricultural areas in the hinterland of Dubrovnik and to the sea influence due to site microlocation. Deposition of nitrate decreased by $36 \%$ compared to the period 1981-1995, but, surprisingly, deposition of ammonium remained the same. That is the reason why differences in total nitrogen deposition between the northern and southern Adriatic coast in the last decade are not as big as they were in the period 1981-1995 (Djuricic et al. [22]). 

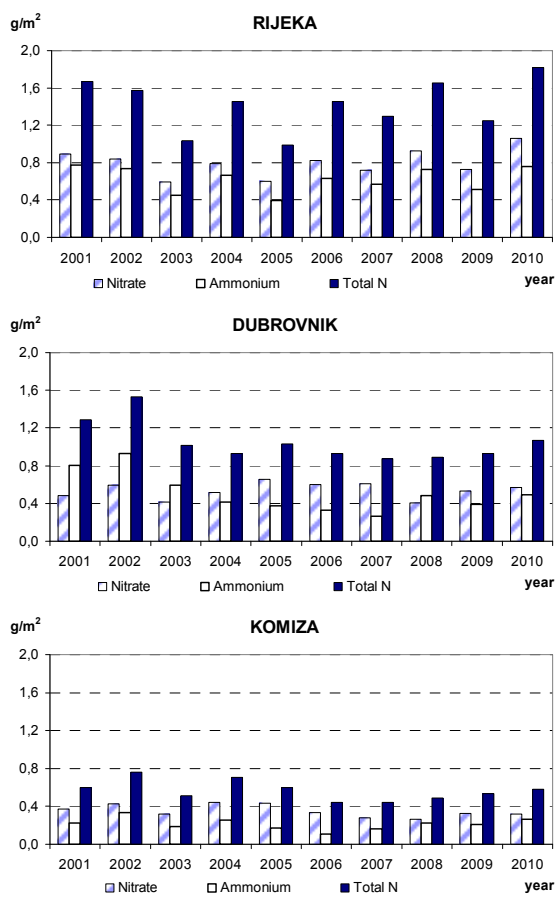

Figure 3: Annual wet deposition of nitrogen from nitrate, ammonium and total $\left(\mathrm{g} / \mathrm{m}^{2}\right)$ in Rijeka, Dubrovnik and Komiza for the period 20012010 .

The southern Adriatic Sea, represented by offshore station Komiza, received the least total nitrogen wet deposition, between 0.44 and $0.76 \mathrm{~g} / \mathrm{m}^{2}$. Most of it belongs to nitrates (54-76\%).

Similar research to this, although more detailed, for the period 1981-1995, in Djuricic et al. [22] showed that the Croatian Adriatic coast was loaded with $1-4 \mathrm{~g} / \mathrm{m}^{2}$ of oxidised and reduced nitrogen. One of the conclusions in that paper was that $1-2 \mathrm{~g} / \mathrm{m}^{2}$ belonged to the influence of long-distance sources and another $1-2 \mathrm{~g} / \mathrm{m}^{2}$ in the northern and mid Adriatic to local pollution sources. Following the same philosophy and considering the offshore station Komiza as a rural/background site, we can conclude that in the period 2001-2010 the Adriatic coast and sea received by wet deposition $0.4-0.8 \mathrm{~g} / \mathrm{m}^{2}$ of total nitrogen from long-distance sources and approximately $0.5 \mathrm{~g} / \mathrm{m}^{2}$ in the south and $1 \mathrm{~g} / \mathrm{m}^{2}$ in the north more from local sources.

\section{Conclusions}

Statistical analysis of $\mathrm{pH}$ and nitrogen compounds in precipitation and their wet deposition for the period 2001-2010, which is the period after the War for Independence, major reconstruction works, decreasing industry and recession, 
and comparison of these results with some previous periods, result in several conclusions:

- The northern Adriatic coast is still under the influence of acid rain.

- Calculated wet deposition of total nitrogen (from nitrates and ammonia) along the Adriatic coast ranges from 0.44 to $1.82 \mathrm{~g} / \mathrm{m}^{2}$. Deposition of 0.4 $0.8 \mathrm{~g} / \mathrm{m}^{2}$ can be considered as the result of the influence of long-distance sources. Local pollution sources contribute with additional $0.5 \mathrm{~g} / \mathrm{m}^{2}$ on the southern coast to $1 \mathrm{~g} / \mathrm{m}^{2}$ on the northern coast.

- Deposition of nitrates prevails with $50-70 \%$ in total nitrogen wet deposition.

- Wet deposition of nitrates in the considered period 2001-2010 is smaller for about $36 \%$ in the southern Adriatic and 50\% in the northern Adriatic compared to the period 1981-1995. Wet deposition of ammonia decreased only in the northern Adriatic by $56 \%$.

Although nitrogen wet deposition along the Adriatic coast has significantly decreased in the last decade compared to the period before 2000, further control of nitrogen emission is still needed, since the Adriatic Sea is one of the areas suffering severe eutrophication problems due to atmospheric nitrogen input of about four times the natural background (Sutton et al. [24].)

\section{References}

[1] Pearl, H.W., Nuisance phytoplankton blooms in coastal, estaurine, and inland waters. Limnol. Oceanogr. 33 (4, part 2), pp. 823-847, 1988.

[2] Eskinja, I., Soljic, Z., Svel-Cerovecki, S., Eskinja, M. \& Sojat, V., Sources and fate of polycyclic aromatic hydrocarbons in ambient air of urban and rural Croatian sites. Intern. Journ. Environ. Analytical Chem., 63, pp. 251268, 1996.

[3] Pearl, H.W., Enhancement of marine production by nitrogen-enriched acid rain. Nature, 315, pp. 747-749, 1985.

[4] Knap, A., Jickells, T., Pszenny, A. \& Galloway, J.N., Significance of atmospheric-derived nitrogen on productivity of the Sargasso Sea. Nature, 320, pp. 158-160, 1986.

[5] Fanning, K., Influence of atmospheric pollution on nutrient limitation in the ocean. Nature, 339, pp. 460-463, 1989.

[6] Pearl, H.W., Rudek, J. \& Mallin, M.A., Stimulation of phytoplankton production in coastal waters by natural rainfall inputs: Nutritional and trophic implications. Marine Biology, 107, pp. 247-254, 1990.

[7] Willey, J.D. \& Cahoon, L.B., Enhancement of chlorophyll production in Gulf Stream surface seawater by rain-water nitrate. Marine Chemistry, 34, pp. 63-75, 1991.

[8] Owens, N.J.P., Galloway, J.N. \& Duce, R.A., Episodic atmospheric nitrogen deposition to oligotrophic oceans. Nature, 357, pp. 397-399, 1992.

[9] Michaels, A.F., Siegel, D.A., Johnson, R., Knap, A.H. \& Galloway, J.N., Episodic inputs of atmospheric nitrogen to Saragosso Sea: Contribution to new production and phytoplankton blooms. Global Biogeochemical Cycles, 7, pp. 339-351, 1993. 
[10] Fisher, D.C. \& Oppenheimer, M., Atmospheric nitrogen deposition at the Chesapeake Bay estuary. Ambio, 20, pp. 102-108, 1991.

[11] Hinga, K.R., Keller, A.A. \& Oviatt, C.A., Atmospheric deposition and nitrogen inputs to coastal waters. Ambio, 20, pp. 256-260, 1991.

[12] Smodlaka, N., Outlines for a proposal of the Croatian monitoring programme, Report of the consultation meeting on the evaluation of the Croatian monitoring programme. UNEP (OCA)/ MED WG. 80/2., Annex VIII, 1994.

[13] Erdman, L. et al, Assessment of Airborne Pollution of the Mediterranean Sea by Sulphur and Nitrogen Compounds and Heavy Metals in 1991. MAP Technical Reports Series No.85, UNEP, Athens, 303 pp. 1994.

[14] Bajic, A., \& Djuricic, V., Precipitation Chemistry and Atmospheric Processes in the Forested Part of Croatia. Water, Air and Soil Pollution, 85 (1-4), pp. 1955-1960, 1995.

[15] Vidic, S., Deposition of Sulphur and Nitrogen Compounds in Croatia. Water, Air and Soil Pollution, 85, (1-4), pp. 2179-2184, 1995.

[16] Alebic-Juretic, A. \& Sojat, V., Chemical Composition of Rainwater Collected at Two sampling Sites within the City of Rijeka. Proc. of the 1st Croatian Conference on Air Protection 97, pp. 409-413, 1997.

[17] Sojat, V., Vidic, S., Hrabak-Tumpa, G. \& Borovecki, D., Acid Precipitation in the Kvarner Area Region. Proc. of the 15th Int. Scientific Conf. Energy and the Environment, pp. 471-478, 1996.

[18] Pozar-Domac, A. et al, The Silba Marine Park - preliminary research of the main characteristics of the area, establishment of specially protected area, and marine park managing organisation. Periodicum Biologorum, 100, 1, pp. 7-18, 1998.

[19] Sojat, V. \& Borovecki, D., Chemical Composition and Characteristics of Precipitation in Rijeka, Senj and Sibenik Raingauge Stations. Proc. of the 1st Croatian Conference on Waters Sustainable Development and Water Management, pp. 561-568, 1995.

[20] EMEP/CCC Report 1/95, EMEP Manual for sampling and chemical analysis. NILU, 1996, Revision 1/2001.

[21] Zaninovic, K. (ed) et al, Climate atlas of Croatia 1961-1990., 1971-2000. Meteorological and Hydrological Service, Zagreb, 200 pp.

[22] Djuricic, V., Sojat, V., Vidic, S. \& Guerzoni, S., Atmospheric input of inorganic nitrogen to the Adriatic Sea. In Atmospheric transport and deposition of pollutants into the Mediterranean Sea, Final Reports on research projects, MAP Technical Report Series, 33, pp. 86-113.

[23] Spoler Canic, K., Vidic, S. \& Bencetic Klaic, Z., Precipitation chemistry in Croatia during the period 1981-2006. Journal of Environmental Monitoring, 11, pp. 839-851, 2009.

[24] Sutton, M.A., Howard, C.M., Erisman, J.W., Billen, G., Bleeker, A., Grennfelt, P., van Grinsven, H. \& Grizzetti, B., The European Nitrogen Assessment, Cambridge University Press, 612 pp. 2011.

[25] EMEP/MSC-W Report 1/97, NILU, 1996. 